\title{
Microbiome Associated with Slovak Traditional Ewe's Milk Lump Cheese
}

\author{
Andrea Lauková ${ }^{1, *(D)}$, Lenka Micenková ${ }^{2}$, Monika Pogány Simonová ${ }^{1}\left(\right.$, Valentína Focková $^{1}\left(\right.$, Jana Ščerbová $^{1}$, \\ Martin Tomáška ${ }^{3}$, Emília Dvorožňáková ${ }^{4}$ and Miroslav Kološta ${ }^{3}$ \\ 1 Institute of Animal Physiology, Centre of Biosciences of the Slovak Academy of Sciences, Šoltésovej 4-6, \\ 04001 Košice, Slovakia; simonova@saske.sk (M.P.S.); fockova@saske.sk (V.F.); scerbova@saske.sk (J.Š.) \\ 2 RECETOX, Faculty of Science, Masaryk University, Kamenice 5, 62500 Brno, Czech Republic; \\ micenkova@recetox.muni.cz \\ 3 Research Dairy Institute, a.s. Dlhá 95, 01000 Žilina, Slovakia; martin.tomaska@vumza.sk (M.T.); \\ miroslav.kolosta@vumza.sk (M.K.) \\ 4 Parasitological Institute of the Slovak Academy of Sciences, Šoltésovej 4-6, 04001 Košice, Slovakia; \\ dvoroz@saske.sk \\ * Correspondence: laukova@saske.sk; Tel.: +421-557-922-964; Fax: +421-557-827-842
}

check for updates

Citation: Lauková, A.; Micenková, L.; Pogány Simonová, M.; Focková, V.; Ščerbová, J.; Tomáška, M.;

Dvorožňáková, E.; Kološta, M.

Microbiome Associated with Slovak Traditional Ewe's Milk Lump Cheese. Processes 2021, 9, 1603. https:// doi.org/10.3390/pr9091603

Academic Editors: Nevijo Zdolec and Wei Ma

Received: 8 June 2021

Accepted: 6 September 2021

Published: 7 September 2021

Publisher's Note: MDPI stays neutral with regard to jurisdictional claims in published maps and institutional affiliations.

Copyright: (c) 2021 by the authors. Licensee MDPI, Basel, Switzerland. This article is an open access article distributed under the terms and conditions of the Creative Commons Attribution (CC BY) license (https:/ / creativecommons.org/licenses/by/ $4.0 /)$.

\begin{abstract}
Worldwide consumers increasingly demand traditional/local products, to which those made from ewe's milk belong. In Slovakia, dairy products made from ewe's milk have a long tradition. A total of seventeen farmhouse fresh ewe's milk lump cheeses from various local farm producers in central Slovakia were sampled at farms and then analyzed. Based on the sequencing data analysis, the phylum Firmicutes dominated (60.92\%) in ewe's lump cheeses, followed with the phylum Proteobacteria (38.23\%), Actinobacteria (0.38\%) and Bacteroidetes $(0.35 \%)$. The phylum Firmicutes was represented by six genera, among which the highest amount possessed the genus Streptococcus (41.13\%) followed with the genus Lactococcus (8.54\%), Fructobacillus (3.91\%), Enterococcus $(3.18 \%)$, Staphylococcus $(1.80 \%)$ and the genus Brochotrix $(0.08 \%)$. The phylum Proteobacteria in ewe's lump cheeses involved eight Gram-negative genera: Pseudomonas, Acinetobacter, Enterobacter, Ewingella, Escherichia-Shigella, Pantoea and Moraxella. The phylum Bacteroidetes involved three genera: Bacteroides, Sphingobacterium and Chrysobacterium. Results presented are original; the microbiome of Slovak ewe's milk lump cheese has been not analyzed at those taxonomic levels up to now.
\end{abstract}

Keywords: ewe; milk lump cheese; microbiome

\section{Introduction}

Nowadays, consumers increasingly demand traditional products made from ewe's milk. Milk from farm animals and dairy products is a highly nutritious food [1,2], a staple component of human nutrition. However, food safety has become an issue of intensive interest worldwide. Eminent attention is focused on the microbial population in those products. This is because bacteria can show their beneficial potential (production of bacteriocins, probiotic character) but, on the other hand, damaging potential (virulence factor genes presence, drug-resistant genes, etc.), which can threaten human health. Therefore, understanding of the microbiome of products provides information potential for basic science on one hand; on the other hand, it provides information for consumers. It is also a signal to researchers and producers to research how to prevent/avoid/reduce contamination.

In Slovakia, dairy products made from ewe's milk include, e.g., traditional cheeses such as "parenica", "korbáčik" "oštiepok", and Liptauer bryndza, and also ewe's milk lump cheese, either fresh or smoked [3-5]. "Parenica", "korbáčik" "oštiepok" and Liptauer bryndza, as well as Oravian korbáčik cheese and Zázrivá korbáčik cheese, were designed to be PGI products, meaning products with protected geographical indication [6,7]. Fresh ewe's milk lump cheese has been given the TSG label since November 2010, meaning 
traditional speciality guaranteed [7]. Processing of fresh soft ewe's milk lump cheese consists of the several phases, described in detail in the previous study [4]. This cheese derives its characteristic taste as a result of the traditional technology used during its fermentation and from being shaped by hand into a lump [6]. In general, cheese as a product has a diverse microbial community, which indeed can vary within the cheese from the core to the surface, which is greatly influenced by manufacturing conditions, including ripening conditions. Understanding the composition of this community (microbiota), and its impact on the quality and safety of cheese products, is of critical importance. In addition to, in the majority of cases, consciously added starter and adjunct bacteria (which are added as a supplement), cheese contains a heterogeneous variety of other, non-starter, microorganisms. These various microbiota can play vital roles in the development of the organoleptic properties of cheese, nutrient composition, shelf-life, and safety [8]. The bacterial population in those cheeses has been already studied [2,5] using the standard microbiological method.

However, information describing the microbiome of Slovak ewe's milk lump cheeses analyzed by next-generation sequencing has not been reported up to now. Therefore, the aim of this study was to analyze the microbiome of local ewe's milk lump cheeses using the formerly mentioned sequencing technique.

\section{Materials and Methods}

A total of seventeen farmhouse fresh ewe's milk lump cheeses from local farm producers in central Slovakia were sampled at farms and transported in our laboratory. After being transported to the laboratory in a refrigerating box, the appropriate volume $(100 \mathrm{~g})$ of samples was frozen until further analyses. Individual samples of cheeses were marked as OS1, OS4, OS6, OS8, OS9, OS10, OS11, OS13, OS14, OS15, OS17, OS19, OS51, OS54, OS80, OS94, and OSun following different producers (Figure 1). The appropriate amount of each farmhouse fresh ewe's milk lump soft cheese was homogenized (Stomacher, Masticator, IUL Instruments, Barcelona, Spain). A total of $260 \mu \mathrm{L}$ of homogenized cheese sample was transferred into $2 \mathrm{~mL}$ tubes and $750 \mu \mathrm{L}$ of bead solution and $60 \mu \mathrm{L}$ of $\mathrm{C} 1$ (kit DNeasy PowerLyzer buffer, QIAGEN, Hilden, Germany) were added to each sample. Next, the total volume was transferred to the bead tubes, and DNA isolation was performed using a DNeasy PowerLyzer PowerSoil Kit (QIAGEN, Hilden, Germany) according to the manufacturer's protocol. Isolated DNA was used as a template in PCR reaction (targeting the hypervariable V4 region of the bacterial $16 \mathrm{~S}$ rRNA gene according to the $16 \mathrm{~S}$ Metagenomic Sequencing Library Preparation protocol (Illumina, San Diego, CA, USA). The PCR detection protocol and reagents are shown in Table S1. The primer pairs used are listed in Table 1. Sequencing was performed using MiSeq reagents Kits v2 on a MiSeq 2000 sequencer according to the manufacturers' instructions (Illumina, San Diego, CA, USA).

Table 1. List of primers.

\begin{tabular}{ccccccc}
\hline \multirow{2}{*}{ EMP16S-1 } & F & TCGTCGGCAGCGTCAGATGTGTATAAGAGACAGAGCCTTCGTCGCGTGTGYCAGCMGCCGCGGTAA \\
& R & GTCTCGTGGGCTCGGAGATGTGTATAAGAGACAGCCTAACGGTCCACCGGACTACNVGGGTWTCTAAT \\
EMP16S-2 & F & TCGTCGGCAGCGTCAGATGTGTATAAGAGACAGTCCATACCGGAAGTGTGYCAGCMGCCGCGGTAA \\
& R & GTCTCGTGGGCTCGGAGATGTGTATAAGAGACAGCGCGCCTTAAACCCGGACTACNVGGGTWTCTAAT \\
EMP16S-3 & F & TCGTCGGCAGCGTCAGATGTGTATAAGAGACAGAGCCCTGCTACAGTGTGYCAGCMGCCGCGGTAA \\
& R & GTCTCGTGGGCTCGGAGATGTGTATAAGAGACAGTATGGTACCCAGCCGGACTACNVGGGTWTCTAAT \\
EMP16S-4 & F & TCGTCGGCAGCGTCAGATGTGTATAAGAGACAGTGAGACCCTACAGTGTGYCAGCMGCCGCGGTAA \\
& R & GTCTCGTGGGCTCGGAGATGTGTATAAGAGACAGGCCTCTACGTCGCCGGACTACNVGGGTWTCTAAT \\
EMP16S-5 & F & TCGTCGGCAGCGTCAGATGTGTATAAGAGACAGACTTGGTGTAAGGTGTGYCAGCMGCCGCGGTAA \\
& R & GTCTCGTGGGCTCGGAGATGTGTATAAGAGACAGACTACTGAGGATCCGGACTACNVGGGTWTCTAAT & 16S Metagenomic sequencing \\
EMP16S-6 & F & TCGTCGGCAGCGTCAGATGTGTATAAGAGACAGATTACGTATCATGTGTGYCAGCMGCCGCGGTAA \\
& R & GTCTCGTGGGCTCGGAGATGTGTATAAGAGACAGAATTCACCTCCTCCGGACTACNVGGGTWTCTAAT & Preparation protocol; Illumina, \\
EMP16S-7 & F & TCGTCGGCAGCGTCAGATGTGTATAAGAGACAGCACGCAGTCTACGTGTGYCAGCMGCCGCGGTAA \\
& R & GTCTCGTGGGCTCGGAGATGTGTATAAGAGACAGCGTATAAATGCGCCGGACTACNVGGGTWTCTAAT \\
EMP16S-8 & F & TCGTCGGCAGCGTCAGATGTGTATAAGAGACAGTGTGCACGCCATGTGTGYCAGCMGCCGCGGTAA \\
& R & GTCTCGTGGGCTCGGAGATGTGTATAAGAGACAGATGCTGCAACACCCGGACTACNVGGGTWTCTAAT \\
EMP16S-9 & F & TCGTCGGCAGCGTCAGATGTGTATAAGAGACAGCCGGACAAGAAGGTGTGYCAGCMGCCGCGGTAA \\
& R & GTCTCGTGGGCTCGGAGATGTGTATAAGAGACAGACTCGCTCGCTGCCGGACTACNVGGGTWTCTAAT \\
EMP16S-10 & F & TCGTCGGCAGCGTCAGATGTGTATAAGAGACAGTTGCTGGACGCTGTGTGYCAGCMGCCGCGGTAA \\
& R & GTCTCGTGGGCTCGGAGATGTGTATAAGAGACAGTTCCTTAGTAGTCCGGACTACNVGGGTWTCTAAT \\
EMP16S-11 & F & TCGTCGGCAGCGTCAGATGTGTATAAGAGACAGTACTAACGCGGTGTGTGYCAGCMGCCGCGGTAA \\
& R & GTCTCGTGGGCTCGGAGATGTGTATAAGAGACAGCGTCCGTATGAACCGGACTACNVGGGTWTCTAAT &
\end{tabular}


Table 1. Cont.

\begin{tabular}{ccc}
\hline \multirow{2}{*}{ EMP16S-12 } & F & TCGTCGGCAGCGTCAGATGTGTATAAGAGACAGGCGATCACACCTGTGTGYCAGCMGCCGCGGTAA \\
& R & GTCTCGTGGGCTCGGAGATGTGTATAAGAGACAGACGTGAGGAACGCCGGACTACNVGGGTWTCTAAT \\
EMP16S-13 & F & TCGTCGGCAGCGTCAGATGTGTATAAGAGACAGCAAACGCACTAAGTGTGYCAGCMGCCGCGGTAA \\
& R & GTCTCGTGGGCTCGGAGATGTGTATAAGAGACAGGGTTGCCCTGTACCGGACTACNVGGGTWTCTAAT \\
EMP16S-14 & F & TCGTCGGCAGCGTCAGATGTGTATAAGAGACAGGAAGAGGGTTGAGTGTGYCAGCMGCCGCGGTAA \\
& R & GTCTCGTGGGCTCGGAGATGTGTATAAGAGACAGCATATAGCCCGACCGGACTACNVGGGTWTCTAAT \\
EMP16S-15 & F & TCGTCGGCAGCGTCAGATGTGTATAAGAGACAGTGAGTGGTCTGTGTGTGYCAGCMGCCGCGGTAA \\
& R & GTCTCGTGGGCTCGGAGATGTGTATAAGAGACAGGCCTATGAGATCCCGGACTACNVGGGTWTCTAAT \\
\hline
\end{tabular}

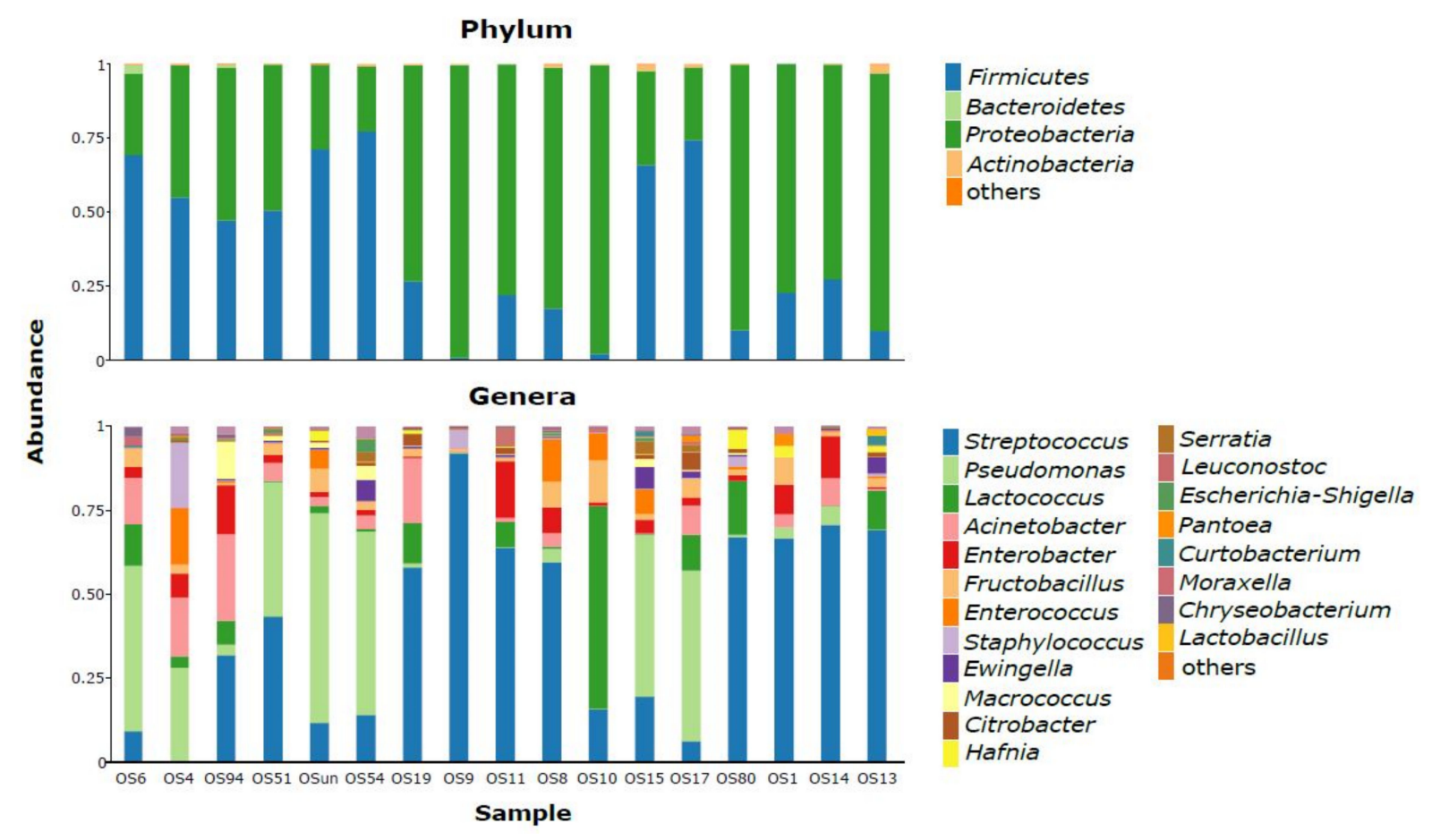

Figure 1. Detection of microbiota at the levels of phyla and genera (individual cheeses are also indicated in Section 2).

Sequence pre-processing included quality trimming using a Trimmomatic sequence tool [9], subsequent joining by the fastq-join utility [10], and demultiplexing. In the final step, joined reads were subjected to operational taxonomic unit (OTU) picking with a 97\% sequence similarity threshold. OTU picking was performed using the tool uclust [11]. OTU picking was followed by taxonomy assignment using the usearch-based [11] method of the QIIME 1.9.1 [12] toolset against the Siva v 123 16S rRNA database [13].

\section{Results and Discussion}

Based on sequencing data, the phylum Firmicutes dominated (60. 92\%) in ewe's milk lump cheeses, followed by the phylum Proteobacteria (38. 23\%, Table 2 and Figure 2). The other phyla were detected in slight amounts: Actinobacteria (0.38\%) and Bacteroidetes $(0.35 \%$, Table 2 and Figure 2). The phylum Firmicutes was represented by six (6) involved genera (Figure 3), among which the highest amount possessed the genus Streptococcus $(41.13 \%)$. This genus belongs to the class Bacilli, the order Lactobacillalles and to the family Streptococcacae. Regarding individual cheeses, the OS9 cheese possessed the highest percentage amount of streptococci, while the lowest amount was detected in the cheese OS17 (Figure 1). The cheese OS4 was even streptococci absent. Streptococci are helpful bacteria and their different occurrences in individual cheeses can be influenced by their amount in ewe's milk. The second most frequently detected genus in Slovak traditional ewe's milk lump cheeses was the genus Lactococcus (8.54\%, Figures 1 and 3). However, its amount was much lower compared with the genus Streptococcus (Figures 1 and 3, Table 2). The genus Lactococcus also belongs to the class Bacilli and the order Lactobacillales. The genus Fructobacillus was the third most frequently occurring microbial representative in 
ewe's milk lump cheeses (3.91\%, Figures 1 and 3), belonging again to the same class and order, but to the family Leuconostocacae [14]. The detection of lactobacilli and leuconostoc was very slight in the individual ewe's lump cheeses (Figures 1 and 3). However, those formerly mentioned genera belong to helpful/beneficial microbiota in milk, e.g., representatives of the genera Streptococcus, Leuconostoc or Lactobacillus are able to utilize lactose which is broken down in the lactic acid [1]. Streptococci, lactococci and lactobacilli belong to Gram-positive bacteria which can be commonly detected in cheeses, especially in those produced with starter cultures [15]. The genus Enterococcus belonging in the family Enterococcacae was detected in tested cheeses in the amount of 3.18\% (Figures 1 and 3). On the one hand, enterococci can be supposed to be contaminant bacteria in cheeses [16-18]; on the other hand, they can serve as probiotic microbiota producing antimicrobial active substances-bacteriocins [2,19]. However, representatives of the genus Staphylococcus are supposed to be frequent inhabitants in cheeses $[4,20]$. They were detected in ewe's lump cheese in the amount of $1.80 \%$ (Table 2, Figures 1 and 3). However, helpful/beneficial microbiota can also cause some technological changes when they are over-produced [2], so their optimal amount is preferred. The genus Brochotrix belonging to the family Listeriacae was evaluated in cheeses in very slight amounts $(0.08 \%)$.

Table 2. Abundance percentage (\%) in the microbiome analyses of ewe's milk lump cheese.

\begin{tabular}{|c|c|c|c|}
\hline \multicolumn{4}{|c|}{ Phylum } \\
\hline Firmicutes (60.92) & Proteobacteria (38.23) & Actinobacteria (0.38) & Bacteroidetes (0.35) \\
\hline \multicolumn{4}{|c|}{ Genera } \\
\hline Streptococcus (41.13) & Pseudomonas (20.70) & Curtobacterium (0.7\%) & $\begin{array}{c}\text { Chryseobacterium } \\
(0.03)\end{array}$ \\
\hline Lactococcus (8.54) & Acinetobacter (6.79) & & Shingobacterium (0.03) \\
\hline Fructobacillus (3.91) & Enterobacter (5.14) & & Bacteroides (0.001) \\
\hline Enterococcus (3.18) & Ewingella (1.3) & & \\
\hline Staphylococcus (1.80) & $\begin{array}{c}\text { Escherichia-Shigella } \\
(0.55)\end{array}$ & & \\
\hline \multirow[t]{2}{*}{ Brochotrix (0.08) } & Pantoea (0.46) & & \\
\hline & Moraxella (0.31) & & \\
\hline
\end{tabular}

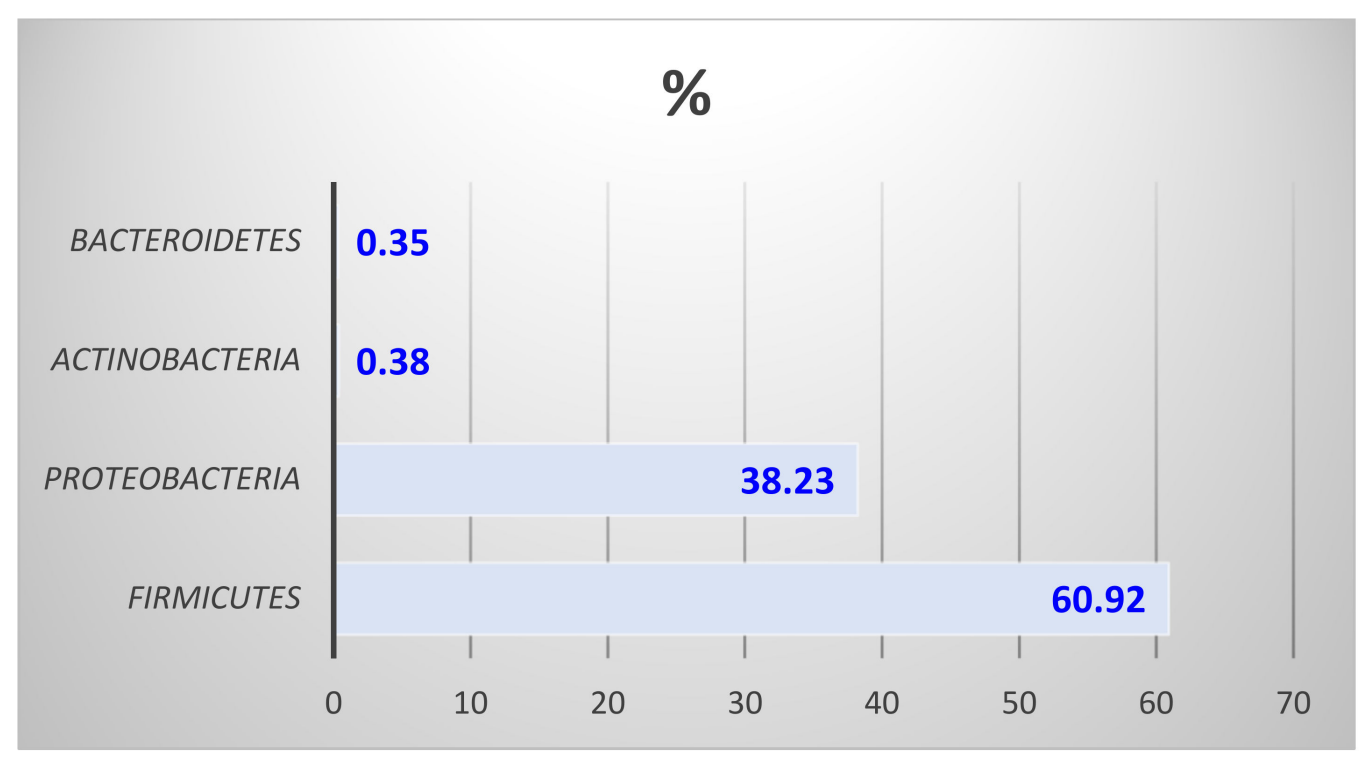

Figure 2. Phyla detected in Slovak ewe's lump cheeses (in percentage). 


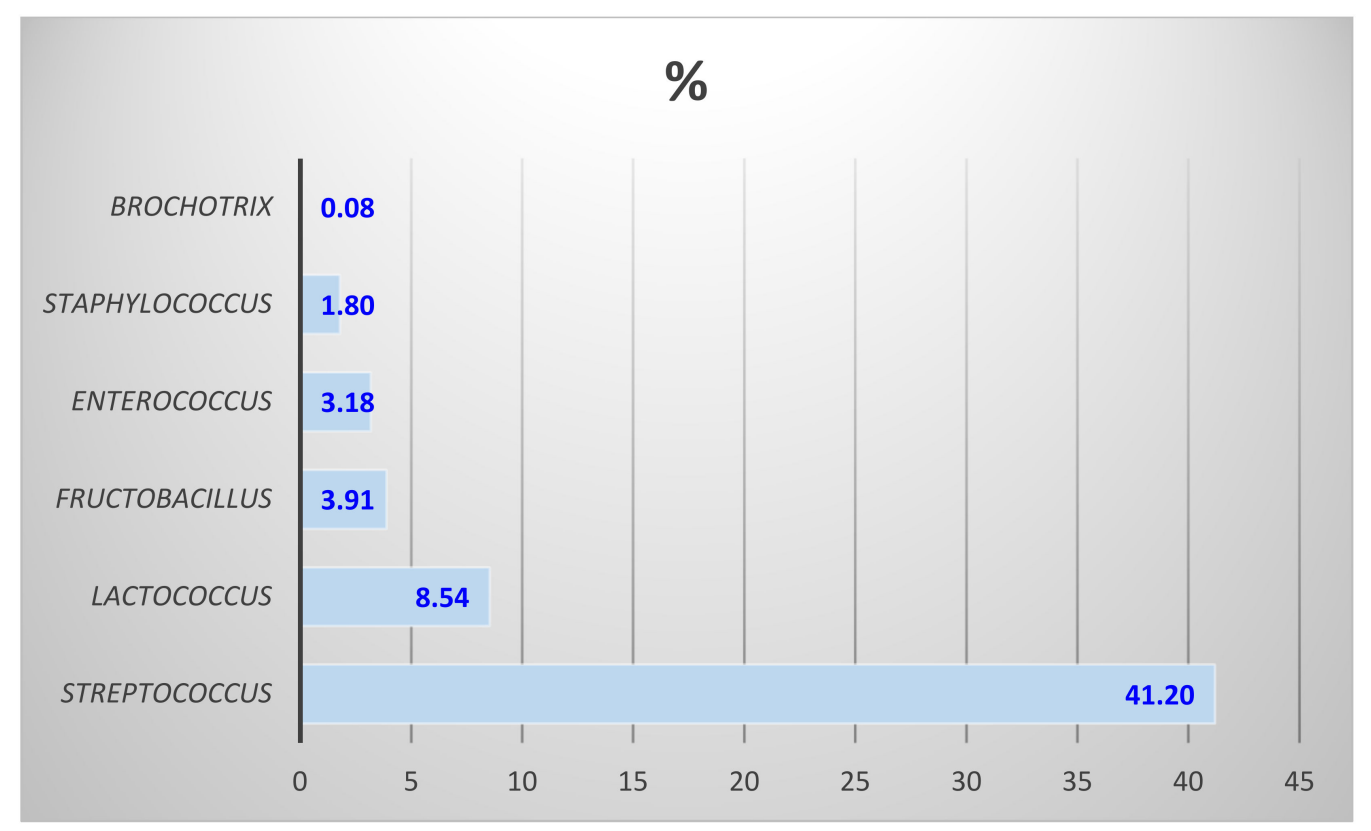

Figure 3. Gram-positive genera detected in Slovak ewe's lump cheeses (in percentage).

However, spoilage bacterial phyla were also detected in analyzed cheeses. The phylum Proteobacteria detected in ewe's milk lump cheeses was represented by eight (8) Gramnegative genera: Pseudomonas, Acinetobacter, Enterobacter, Ewingella, Escherichia-Shigella, Pantoea and Moraxella. Regarding the phylum Proteobacteria, surprisingly, the genus Pseudomonas $(20.7 \%$ ) was evaluated in the highest amount (Table 2, Figures 1 and 4 ) followed by the genera Acinetobacter (6.79\%), Enterobacter (5.14\%), Ewingella (1.3\%), Escherichia-Shigella $(0.55 \%)$, Pantoea $(0.46 \%)$ and Moraxella $(0.31 \%$, Figures 1 and 4 , Table 2$)$. In the phylum Actinobacteria the genus Curtobacterium was evaluated, belonging to the order Actinomycetales/Micrococcales and the family Microbacteriacae [21]. The highest amount of pseudomonads was determined in the cheese OSun, OS6 and OS54 (Figures 1 and 4); on the other hand, in the cheeses OS9 and OS11, these bacteria were not found. Psychrotrophic microbiota such as pseudomonads are able to grow at low temperatures; this can explain their occurrence in cheeses. Pseudomonas spp. can enter cheese, e.g., via water. They produce enzymes which tolerate low temperatures and break down proteins in products. This leads to organoleptic changes. The presence of harmful bacteria can also indicate insufficient hygiene conditions during the manufacturing of cheeses. However, the quality of this type of cheeses can be influenced by external factors, such as the temperature during transportation, the quality of milk, the animals' location, etc. Even in spite of sufficient sanitary condition maintenance, Gram-negative bacteria as well as unfavorable Gram-positive bacteria can contaminate cheeses [22,23]. From those Gram-positive, e.g., representatives of the genus Brochotrix can appear as a consequence of temperature imbalance. However, in ewe's milk lump cheeses, listeriae were not detected. Kačániová et al. [24] reported representatives of the genera Escherichia, Acinetobacter and Enterobacter detected in Liptauer bryndza using the standard microbial technique.

The microbiome in traditional/local farmhouse ewe's milk lump cheeses is a variable community. Gram-positive bacterial genera in fresh ewe's milk lump cheeses are associated with natural occurrence. Commonly, lactic acid bacteria (LAB) are a dominant population in raw milk [25]. Additionally, in the microbiome of ewe's milk lump cheeses, genera belonging to LAB (Lactococcus, Streptococcus and/or Enterococcus) were detected. Salazar et al. [26] used the sequencing method to determine the microbial community associated with Gouda cheese. Based on the percentage of sequence reads, they similarly found the genera Lactococcus, Streptococcus, Staphylococcus and Lactobacillus to be dominant organisms in cheese. Kačániová et al. [24] detected lactococci and staphylococci in 
traditional Liptauer bryndza, which is made from ewe's milk lump cheese. Enterococci are commonly found in high levels in a variety of cheeses produced from raw ewe's milk $[27,28]$. Different species of enterococci isolated from cheeses were able to produce antimicrobial peptides - enterocins [29]; most of them also showed probiotic character [24]. Altogether, this indicates their benefit in the products. Despite the fact that in the ewe's milk lump cheeses tested, the genus Streptococcus was detected in high amounts, no information exists about species representatives in cheese in the literature. In May bryndza cheese, again, only Streptococcus spp. was reported [24]. Planý et al. [30] used metagenomic analysis for Slovak bryndza cheese produced in winter containing ewe's milk lump cheese. They detected a diverse prokaryotic microbiota composed mostly of the genera Lactococcus, Streptococcus, Lactobacillus and Enterococcus. They also detected some Gammaproteobacteria. This indicates a similar composition of cheeses made from ewe's milk.

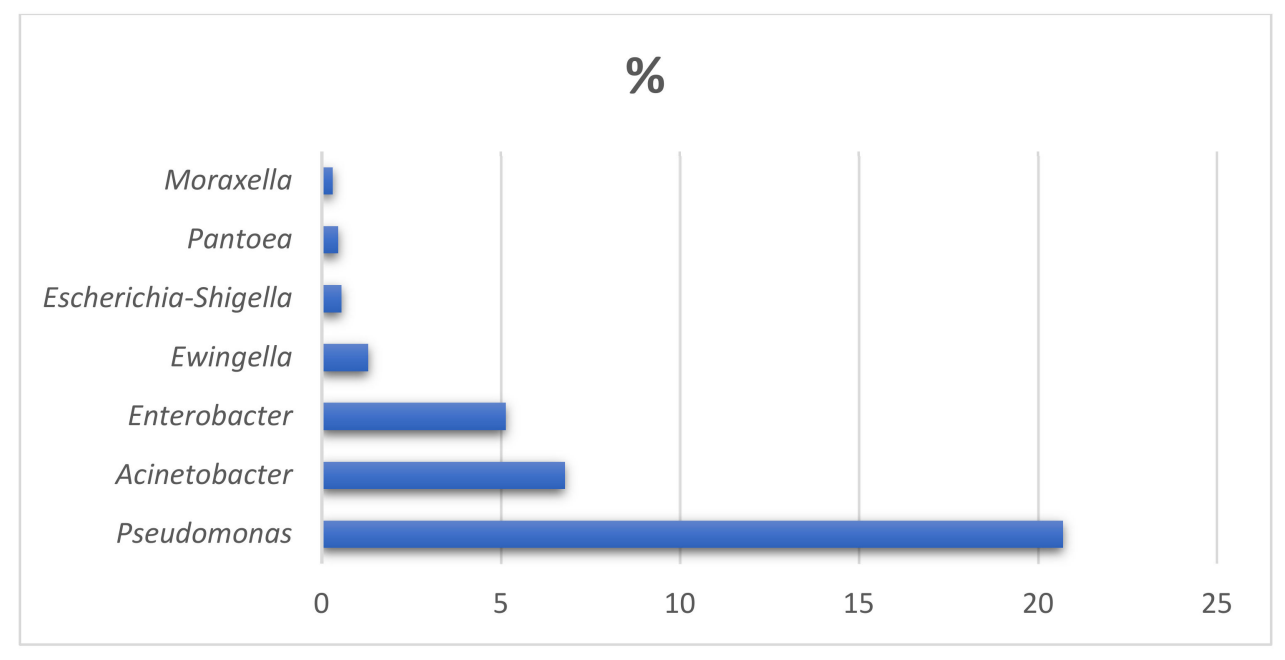

Figure 4. Gram-negative genera detected in Slovak ewe's lump cheese (in percentage).

\section{Conclusions}

The sequencing method allows for microbial consortia in ewe's milk lump cheese to be determined more accurately and shows how the microbiome plays a role in safety and quality. It can be seen that fresh lump cheeses possess many beneficial and non-useful microbiota; however, the phylum Firmicutes and the genus Streptococcus dominate.

Supplementary Materials: The following is available online at https:/ / www.mdpi.com/article/ 10.3390 / pr9091603/s1. It is available in Table S1. The PCR protocol and reagents used in bacterial analysis of ewe's milk lump cheeses.

Author Contributions: Conceptualization, designing, summarizing, writing, project administration; A.L. methodology, sequencing L.M.; investigation, M.P.S., V.F. and J.Š. resources, M.T., M.K. and E.D. All authors have read and agreed to the published version of the manuscript.

Funding: This research was funded by the Slovak Research and Development Agency under contract no. APVV-17-0028 and the RECETOX research infrastructure: the Czech Ministry of Education, Youth and Sports (LM2018121,02.1.01/0.0/0.0/18_046/0015975, and CZ.02.1.01/0.0/0.0/16013/0001761.

Institutional Review Board Statement: Not applicable.

Informed Consent Statement: Not applicable.

Data Availability Statement: Data availability regarding the PCR are in Supplementary Materials Table S1.

Acknowledgments: We are grateful for language editing Andrew Billingham.

Conflicts of Interest: The authors declare no conflict of interest. 


\section{References}

1. Uhrín, V.; Lauková, A.; Jančová, A.; Plintovič, V. Mlieko a Mliečna Žl’aza. Milk and Mammary Gland; Publ. No. 92; Faculty of Natural Sciences of the University Constantinus Philosophus: Nitra, Slovakia, 2002; pp. 5-167, ISBN 80-8050-511-X. (in Slovak)

2. Lauková, A.; Focková, V.; Simonová, M.P. Enterococcus mundtii Isolated from Slovak Raw Goat Milk and Its Bacteriocinogenic Potential. Int. J. Environ. Res. Public Health 2020, 17, 9504. [CrossRef]

3. Herian. Benefit of sheep milk products to human health. Milk Lett. Mlékařské Listy 2014, 143, 1-6. (In Slovak)

4. Lauková, A.; Simonová, M.P.; Focková, V.; Kološta, M.; Tomáška, M.; Dvorožňáková, E. Susceptibility to Bacteriocins in Biofilm-Forming, Variable Staphylococci Isolated from Local Ewe's Milk Lump Cheeses. Foods 2020, 9, 1335. [CrossRef] [PubMed]

5. Vatačšinová, T.; Pipová, M.; Fraqueza, M.J.R.; Mal'a, P.; Dudríková, E.; Drážovská, M.; Lauková, A. Short communication: Antimicrobial Potential of Lactobacillus plantarum Strains Isolated from Slovak Raw Sheep Milk Cheeses. J. Dairy Sci. 2020, 103, 6900-6903. [CrossRef] [PubMed]

6. Supeková, S.; Honza, M.; Kačenová, D. Perception of Slovak Foodstuffs Designated by Protected Geographical Indication by Slovak Consumers. J. Food Nutr. Res. 2008, 47, 205-208.

7. The Slovak Spectator. 2011. Available online: https:/ /spectator.sme.sk (accessed on 6 August 2021).

8. Fox, P.F.; McSweeney, P.L.H.; Cogan, T.M.; Guinee, T.P. Fundamentals of Cheese Science, 4th ed.; Springer: Boston, MA, USA, 2017; pp. 185-229. ISBN 978-0-8342-1260-2.

9. Bolger, A.M.; Lohse, M.; Usadel, B. Trimmomatic: A Flexible Trimmer for Illumina Sequence Data. Bioinformatics 2014, 30, 2114-2120. [CrossRef] [PubMed]

10. Aronesty, E. Ea-utils. “Command-Line Tools for Processing Biological Sequencing Data". Available online: https://github.com/ ExpressionAnalysis/ea-utils (accessed on 20 June 2020).

11. Edgar, R.C. Search and clustering orders of magnitude faster than BLAST. Bioinformatics 2010, 26, 2460-2461. [CrossRef]

12. Caporaso, J.G.; Kuczynski, J.; Stombaugh, J.; Bittinger, K.; Bushman, F.D.; Costello, E.K.; Fierer, N.; Peña, A.G.; Goodrich, J.K.; Gordon, J.I.; et al. QIIME allows analysis of high-throughput community sequencing data. Nat. Meth. 2010, 7, 335-336. [CrossRef]

13. Quast, C.; Pruesse, E.; Yilmaz, P.; Gerken, J.; Schweer, T.; Yarza, P.; Peplies, J.; Glockner, F.O. The SILVA ribosomal RNA gene database project: Improved data processing and web-based tools. Nucl. Acids Res. 2013, 41, D590-D596. [CrossRef]

14. Endo, A.; Dicks, L.M.T. Lactic Acid Bacteria: Biodiversity and Taxonom; Holzapfel, W.H., Wood, B.J.B., Eds.; Wiley-Blackwell: Hoboken, NJ, USA, 2014; p. 632, ISBN 9781444333831.

15. Bouton, Y.; Buchin, S.; Duboz, G.; Pochet, S.; Beuvier, E. Effect of mesophilic lactobacilli and enterococci adjunct cultures on the final characteristics of a microfiltered milk Swiss-type cheese. Food Microbiol. 2009, 26, 183-191. [CrossRef]

16. Tofalo, R.; Schirone, M.; Fasoli, G.; Perpetuini, G.; Patrignani, F.; Manetta, A.C.; Lanciotti, R.; Corsetti, A.; Martino, G.; Suzzi, G. Influence of pig rennet on proteolysis, organic acids content and microbiota of Pecorino di Farindola, a traditional Italian ewe's raw milk cheese. Food Chem. 2015, 175, 121-127. [CrossRef] [PubMed]

17. Tofalo, R.; Perpetuini, G.; Battistelli, N.; Pepe, A.; Ianni, A.; Martino, G.; Suzzi, G. Accumulation $\gamma$-Aminobutyric Acid and Biogenic Amines in a Traditional Raw Milk Ewe's Cheese. Foods 2019, 8, 401. [CrossRef]

18. Tsanasidou, C.; Asimakoula, S.; Sameli, N.; Fanitsios, C.; Vandera, E.; Bosnea, L.; Koukkou, A.-I.; Samelis, J. Safety Evaluation, Biogenic Amine Formation, and Enzymatic Activity Profiles of Autochthonous Enterocin-Producing Greek Cheese Isolates of the Enterococcus faecium/durans Group. Microorganisms 2021, 9, 777. [CrossRef]

19. Franz, C.M.A.P.; Huch, M.; Abriouel, H.; Holzapfel, W.; Gálvez, A. Enterococci as probiotics and their implications in food safety. Int. J. Food Microbiol. 2011, 151, 125-140. [CrossRef] [PubMed]

20. Issa, G.; Aksu, H. Detection of Methicillin-Resistant Staphylococcus aureus in Milk by PCR-Based Phenotyping and Genotyping. Acta Veterinaria Eurasia 2020, 46, 120-124. [CrossRef]

21. Chase, A.B.; Arevalo, P.; Polz, M.F.; Berlemont, R.; Martiny, J.B.H. Evidence for Ecological Flexibility in the Cosmopolitan Genus Curtobacterium. Front. Microbiol. 2016, 7, 1874. [CrossRef]

22. Quigley, L.; O'Sullivan, O.; Stanton, C.; Beresford, T.P.; Ross, R.P.; Fitzerald, G.F.; Cotter, P.D. The complex microbiota of raw milk. FEMS Microbiol. 2013, 37, 664-698. [CrossRef]

23. Kazeminia, M.; Mahmoudi, R.; Ghajarbeygi, P.; Mousavi, S. The effect of seasonal variation on the chemical and microbial quality of raw milk samples used in Qazvin. Iran. J. Chem. Health Risk 2019, 9, 157-165.

24. Kačániová, M.; Kunová, S.; Štefánikova, J.; Felšociová, S.; Godovčíková, L.; Horská, E.; Nagyová, L'.; Haščík, P.; Terentjeva, M. Microbiota of the traditional Slovak sheep cheese "Bryndza". J. Microbiol. Biotechnol. Food Sci. 2019, 9, 482-486. [CrossRef]

25. Šaková, N.; Sádecká, J.; Lejková, J.; Puškárová, A.; Koreňová, J.; Kolek, E.; Valík, L'.; Kuchta, T.; Pangallo, D. Characterization of May bryndza cheese from various regions in Slovakia based on microbial, molecular and principal volatile odorants examinations. J. Food Nutr. Sci. 2015, 54, 239-251.

26. Salazar, J.K.; Carstens, C.K.; Ramachadran, P.; Shazer, A.G.; Narula, S.S.; Reed, E.; Ottesen, A.; Schill, K.M. Metagenomics of pasteurized and unpasteurized gouda cheese using targeted 16S rDNA sequencing. BMC Microbiol. 2018, 18, 189. [CrossRef] [PubMed]

27. Gelsomino, R.; Vancanneyet, M.; Condon, S.; Swings, J.; Cogan, T.M. Enterococcal diversity in the environment of an Irish Cheddar-type cheesemaking factory. Int. J. Food Microbiol. 2001, 71, 177-188. [CrossRef]

28. Lauková, A.; Kandričáková, A.; Bino, E.; Tomáška, M.; Kološta, M.; Kmet', V.; Strompfová, V. Some safety aspects of enterococci isolated from Slovak lactic acid dairy product "žinčica". Folia Microbiol. 2020, 65, 79-85. [CrossRef] [PubMed] 
29. Foulquié-Moreno, M.R.; Sarantinopoulos, P.; Tsakalidou, E.; De Vuyst, L. The role and application of enterococci in food and health. Int. J. Food Microbiol. 2006, 106, 1-24. [CrossRef] [PubMed]

30. Planý, M.; Kuchta, T.; Šoltýs, K.; Szemes, T.; Pangallo, D.; Siekel, P. Metagenomics analysis of Slovak bryndza cheese using next-generation 16S rDNA amplicon sequencing. Nova Biotechnol. Chim. 2016, 15, 23-34. [CrossRef] 